\title{
Hacia el encanto del muro con Mauro Rodríguez Cárdenas*
}

\author{
Alicia Valladares Landa \\ Departamento Académico de Arte
}

El muro, un reto, un amigo, un misterio, la nada, sumergirse, encontrarse con lo que planeaste, y mucho más. Ese diálogo silencioso, con miles de voces que te hablan, duendes, la magia del arte, y las figuras llenándose de vida, de tu vida que resuena mítica, más allá del tiempo y del cansancio físico y te sientes pequeño y un ejemplar de los últimos muralistas de su especie, que están en extinción, eso y muche más es lo que dice cuando declara "Soy muralista de profesión", Mauro Rodríguez a sus 66 años, recuerda cómo desde sus cuatro, para él la contemplación tenía un sentido mágico: observar los movimientos, emocionarse, dibujar. Cuando llega al colegio se conmueve ante los hechos históricos y va creciendo admirando el arte del cine y sus protagonistas, todo lo cual le sirve de inspiración para dibujar.

A los trece años muiète sirtpadre y empiez̄a a trabajar en un taller de platería en las vacaciones escolares; el adolescente madura con rapidez, va surgiendo el hombre. A los 16 anos postula a Bellas Artes e ingresa; con la idea de perfeccionar el arte del retrato, pero descubre un mundo maravilloso. Paralelamente trabaja en la sección nocturna en la fábrica de tejidos "El Pacífico", los colores de los hilos van enriqueciendo su retina.

De sus maestros, recuerda a Gomero, Allaín, Gutiérrez Infanta, Dávila y Ugarte Eléspuru, descubre los secretos del oficio y paralelamente se prepara para docente. En su mundo interior en los momentos de silencio, sus vivencias regresan: las frustraciones, alegrías, angustias, las experiencias le sirven para inspirarse, también las corrientes de arte contemporáneo como el expresionismo y el surrealismo, el primero con sus formas atormentadas y el segundo por la soltura y flexibilidad de sus formas, los contrastes violentos de fríos y cálidos y la audacia en el ritmo. 
Egresa de la escuela en 1956 como maestro con medalla de plata e inicia su carrera docente, deja la fábrica de tejidos. Las circunstancias lo ponen ante el requerimiento de tener que preparar un mural. Como no conocía la técnica, se inscribe en el taller de Quispez Asín. Lo que sería un paso fugaz se convirtió en la llave secreta que le llevaría a descubrir su verdadera pasión: el mural; trece años trabajó con Quispez, le enseñó a amar el muro, descubrir sus secretos. Ante él presentó su primer proyecto en 1967, El desarrollo de la educación primaria en el Perú, y lo ejecutó en la escuela $N^{\circ} 753$ de Pueblo Libre, de 6.80 $\mathrm{m}$. de largo por $3.10 \mathrm{~m}$. de alto; luego siguió Alegoría al trabajo $(6.00 \mathrm{~m}$. x $2.50 \mathrm{~m}$.), y hasta que llegó al mural El arte en el Perú.

Los maestros de la escuela de Bellas Artes le fueron brindando su opinión. Su maestro le aconsejó: "Salga al extranjero, el público no está aún preparado para apreciar un mural". Han pasado los años, y en parte su maestro tuvo razón; pero el amor a su tierra y el calor humano que aun se respira entre nosotros, le hizo apostar por eł Perú. Continuaría haciendo murales, sobreponiéndose a las dificultades, no hay concursos públicos, los particulares permiten continuar en la tarea aunque no siempre en las mejores condiciones.

Su consagración internacional vendría en Colombia en 1988 con el mural de la Quinta de Santa Pedro Alejandrino, en homenaje a Bolívar y a su intervención en la independencia. Dos años entre investigación histórica previa y luego 300 horas contra el muro un trabajo fuerte Se levantaba a las 2:00 de la madrugada para iniciar el murat con su equipo, para no concluir hasta las 5:00 p.m., sólo media hora " paráê almuerzo, luego ejereićsos", cenar y descansar para reiniciar el próximo día. No hubieron feriados, el muro no espera, exige, y fueron surgiendo las figuras. Contó con todos los materiales apropiados, tierras especiales para frescos traídas desde Francia. Los $50 \mathrm{~m}$. de largo por $3.20 \mathrm{~m}$. de alto se constituyeron en el mural histórico más largo de toda América Latina.

Han pasado 10 años desde que el maestro no aceptó el nombramiento de docente en la Universidad Nacional de Bogotá, regresó al Perú y trabajó como docente en su Alma Mater. Aún no se le ha brindado la oportunidad de un gran muro en el país, sigue estudiando, investigando, ahora prepara un inventario de los murales de la Universidad Nacional Mayor de San Marcos, como parte del trabajo que se ha impuesto de ubicar todos los murales existentes en Lima, donde las nuevas generaciones puedan estudiar.

Ahora el tiempo es lo más preciado. En el muro el tiempo se acorta y se lucha contra el tiempo, porque es eso. Cuando se termina aún no se está satisfecho y eso es lo que lo lleva a seguir. 


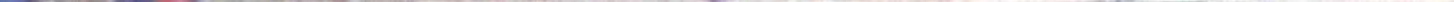




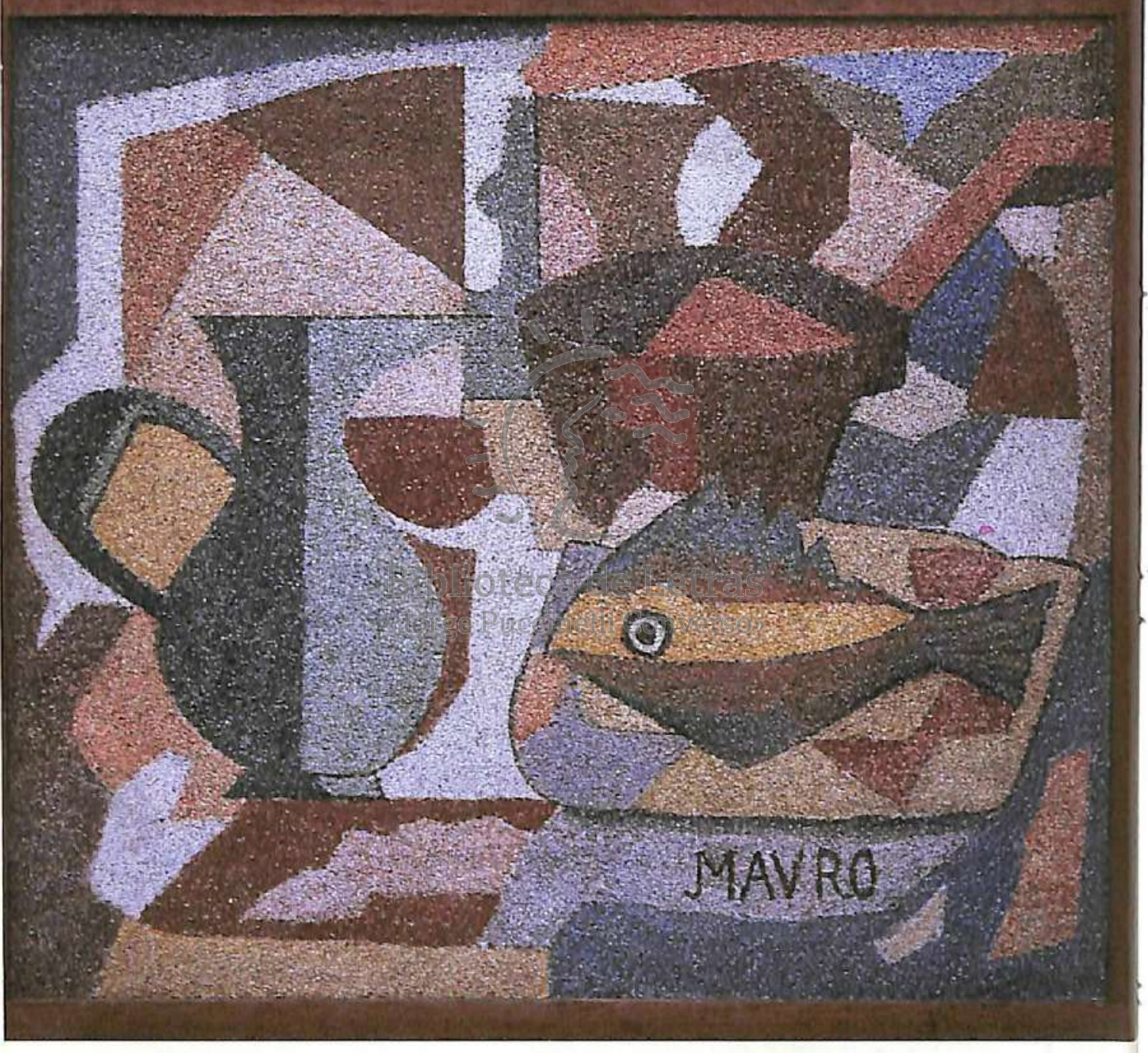

